\title{
Hyperuricemia and Proteinuria in Type 2 Diabetic Patients
}

\author{
Fatya Annisa Haryandini ${ }^{1}$, Tiene Rostini ${ }^{2}$ \\ ${ }^{1}$ Faculty of Medicine, Universitas Padjadjaran, ${ }^{2}$ Department of Clinical Pathology, Faculty of \\ Medicine, Universitas Padjadjaran/Dr. Hasan Sadikin General Hospital, Bandung
}

\begin{abstract}
Background: Type 2 diabetes mellitus (T2DM) is a metabolic disorder that has diabetic nephropathy as a complication characterized by proteinuria. When type 2 diabetic patient's kidney is damaged, hyperuricemia occurs. This study evaluated the correlation of serum uric acid and proteinuria levels in type 2 diabetic patients from outpatient Endocrine clinic at Dr. Hasan Sadikin General Hospital from January to December 2011.

Methods: In a cross-sectional study of 125 patients (55 male and 70 female) with type 2 diabetes mellitus, the data of serum uric acid, fasting plasma glucose, 2-h post oral glucose load plasma glucose, serum highdensity lipoprotein cholesterol, serum trygliceride, and proteinuria levels were accessed from the medical record. Spearman test was used to calculate the correlation of serum uric acid and proteinuria levels. The research used secondary data taken from medical records of patients diagnosed with T2DM from outpatient Endocrine clinic of Department of Internal Medicine at Dr. Hasan Sadikin General Hospital Bandung who had a laboratory examination at Department of Clinical Pathology Dr. Hasan Sadikin General Hospital Bandung from January to December 2011.

Results: The mean age of the type 2 diabetic patients was $61.5 \pm 9.2$ years old, with mean serum uric acid level of $6.2 \pm 1,8 \mathrm{mg} / \mathrm{dl}$, of whom $52.8 \%$ had microalbuminuric and $4.8 \%$ had proteinuria. In type 2 diabetic patients, serum uric acid level correlated positively $(r=0.273)$ with proteinuria $(p=0.002)$.

Conclusions: Higher serum uric acid levels associated significantly positive with a greater probability of proteinuria in type 2 diabetic patients, indicating a potential marker for disease severity.
\end{abstract}

Key words: Proteinuria, type 2 diabetes mellitus, uric acid.

\section{Introduction}

Metabolic syndrome consists of constellation of metabolic abnormalities that increase risk cardiovascular disease (CVD) and diabetes mellitus (DM). The DM is a group of common metabolic disorder characterized by hyperglycemia resulting from insulin secretion disorder, insulin production disorder, or both of them. ${ }^{1}$

In 2030, the World Health Organization (WHO) and International Diabetes Federation (IDF) predicted that the incidence of type 2 diabetes mellitus (T2DM) will increase 2-3 fold from now. ${ }^{2}$ Without a good controlled therapy, T2DM can increases morbidity and mortality. ${ }^{3}$ The chronic hyperglycemia of diabetes is associated with long-term damage, dysfunction, and failure of different organs, especially the eyes, kidneys, nerves, heart, and blood vessels. Long-term complications of diabetes include diabetic nephropathy leading to renal failure. ${ }^{1}$ Diabetic nephropathy is the leading cause of end stage renal disease (ESRD). ${ }^{4}$ A study in America ${ }^{5}$ reported that diabetic nephropathy was one of the highest mortality cause from the many complications of T2DM.

Uric acid is an end product of purine metabolism. ${ }^{6}$ Hyperuricemia is associated with an increased risk of hypertension and cardiovascular disease. ${ }^{7}$ The experimental study with animal model, chronic hyperuricemia can induces kidney injury and hypertension. ${ }^{8}$ Hyperuricemia can result from decreased elimination of uric acid which is caused by decreased of renal excretion, decreased glomerular filtration rate, increased tubular reabsorption, or anion

Correspondence: Fatya Annisa Haryandini, Faculty of Medicine, Universitas Padjadjaran, Jalan Raya BandungSumedang Km.21, Jatinangor, Sumedang, Indonesia, Phone: +628156137181 Email: fatya.annisa.h@gmail.com 
exchange inhibition in diabetic ketoacidosis. ${ }^{7}$ Hyperuricemia induce endothelial dysfunction, glomerular hypertension, renal hypertrophy and isalso associated with the development of glomerulosclerosis. ${ }^{9,10}$ Glomerulosclerosis was founded on a histopathology examination on diabetic nephropathy. ${ }^{11}$ Clinical manifestation of diabetic nephropathy is proteinuria that can be measured by dipstick reagent method. ${ }^{12,13}$ Proteinuria and glomerulosclerosis may develop after prolonged hyperuricemia for 6 months. ${ }^{10}$

Patients with T2DM who probably have diabetic nephropathy are recommended to have their protein levels in the urine examined. Hyperuricemia in T2DM patients occur leading to diabetic nephropathy. The purpose of this study was to evaluate the relationship between serum uric acid and proteinuria in T2DM patients from outpatient Endocrine clinic of Department of Internal Medicineat Dr. Hasan Sadikin General Hospital Bandung from January to December 2011.

\section{Methods}

A cross-sectional study with retrospective approach using secondary data from medical records taken from patients diagnosed with T2DM from outpatient Endocrine clinic of Department Internal Medicine at Dr. Hasan Sadikin General Hospital who had a laboratory examination at the Department of Clinical Pathology of Dr. Hasan Sadikin General Hospital from January to December 2011. Inclusion criteria for subjects in this study was complete medical record data from T2DM patients which consists of age, sex, serum uric acid, fasting plasma glucose, 2-h post oral glucose load plasma glucose, serum high-density lipoprotein cholesterol (HDL-cholesterol), serum trygliceride, and proteinuria levels. Simple random sampling was conducted to get 125 subjects, consisting of 55 male and 70 female, from the total patients with complete medical record data.

The Kolmogorov-Smirnov test was used to evaluate the data distibution of age, serum uric acid, fasting plasma glucose, 2-h post oral glucose load plasma glucose, serum HDLcholesterol, and serum trygliceride levels. When data was normally distributed, mean $\pm S D$ was evaluated and when data was nonnormally distributed, median (interquartile range) was evaluated. Next, proteinuria levels were divided in 3 groups, normoalbuminuric, microalbuminuric and proteinuria.

Relationship between serum uric acid and proteinuria in T2DM patients was determined by using Spearman test. The $\mathrm{p}$ values less than 0.05 were considered significant.

Study permission for this study was obtained from the Research Ethical Committee of Dr. Hasan Sadikin General Hospital Bandung. Time provided for the study was

Table 1 Clinical Characteristics of T2DM patients

\begin{tabular}{lc}
\hline \multicolumn{1}{c}{ Parameters } & Value \\
\hline Gender & \\
Male, $\mathrm{n}(\%)$ & $55(44)$ \\
Female, $\mathrm{n}(\%)$ & $70(56)$ \\
Age (years old) & $61.5 \pm 9.2$ \\
Fasting plasma glucose, mg/dl & $135(51-372)$ \\
2-h post oral glucose load plasma glucose, mg/dl & $180(80-572)$ \\
Serum HDL-cholesterol, mg/dl & $47(24-90)$ \\
Serum trygliseride, mg/dl & $136(43-554)$ \\
Serum uric acid, mg/dl & $6.2 \pm 1.8$ \\
Proteinuria & \\
Normoalbuminuria, $\mathrm{n}(\%)$ & $53(42.4)$ \\
Microalbuminuria, $\mathrm{n}(\%)$ & $66(52.8)$ \\
Proteinuria, $\mathrm{n}(\%)$ & $6(4.8)$ \\
\hline
\end{tabular}

Data are presented as number (percentage), mean \pm SD, median (interquartile range), 2-h: two hours; HDL: high-density lipoprotein 
Table 2 Correlation Between Serum Uric Acid and Other Variables

\begin{tabular}{lcc}
\hline \multicolumn{1}{c}{ Parameters } & R & P \\
\hline Proteinuria & & $0.002^{*}$ \\
All Subjects & 0.273 & 0.431 \\
Male & 0.108 & $0.008^{*}$ \\
Female & 0.314 & $0.007^{*}$ \\
Fasting plasma glucose & -0.242 & $0.002^{*}$ \\
Serum HDL-cholesterol & -0.269 & 0.294 \\
Serum triglyceride & 0.095 & 0.295 \\
\hline
\end{tabular}

*: significant correlation

Correlation is significant at the 0.01 level (2-tailed).

R: correlation; P: significant value; HDL: high-density lipoprotein

from November 20th, 2012-February 20th, 2013.

\section{Results}

Clinical characteristics were recorded from 125 patients with T2DM that consisted of 55 male and 70 female, aged $61.5 \pm 9.2$ The mean of serum uric acid level was higher in male than in female $(7.0 \pm 1.8 \mathrm{mg} /$ dl). Furthermore, there were 53 subjects $(42.4 \%)$ normoalbuminuric, 66 subjects (52.8\%) microalbuminuric and 6 subjects $(4.8 \%)$ proteinuria patients. Serum uric acid for normoalbuminuric, microalbuminuric, and proteinuria patients were $5.8 \pm 1.6 \mathrm{mg} /$ dl, $6.6 \pm 1.9 \mathrm{mg} / \mathrm{dl}, 7.9 \pm 1.7 \mathrm{mg} / \mathrm{dl}$. (Table 1) There were significant relationship between serum uric acid and proteinuria among all subjects and female subjects $(\mathrm{p}=0.002$ and $\mathrm{p}=0.008$ ). Serum uric acid also had significant relationship with fasting plasma glucose and serum HDL-cholesterol ( $\mathrm{p}=0.007$ and $\mathrm{p}=0.002$ ) (Table 2).

\section{Discussions}

Type 2 Diabetes Mellitus has diabetic nephropathy as a complication characterized by proteinuria. ${ }^{4}$ This study shows that serum uric acid and proteinuria have a significantly positive correlation.This result is inline with the study conducted by Tseng et al. $^{7}$ who reported a correlation between serum uric acid and urine albumin-creatinine ratio (UACR) in T2DM patients. Increase of UACR can be prevented by lowering uric acid levels in T2DM patients. Since protenuria is the sign of nephropathy diabetic, ${ }^{13}$ the association of hyperuricemia and UACR pointed out the effect of hyperuricemia on diabetic nephropathy. Bonakdaran et al. ${ }^{9}$ also reported a positive correlation between increased serum uric acid and increased albuminuria level.

In this study, the correlation between serum uric acid and proteinuria was significant among all subjects and female subjects, however not in male subjects, suggesting a different hormonal system between male and female. The age of female subjects can be classified as menopause women, therefore, the hormonal system might have imbalanced estrogen which made kidney injury worsen, as reported by Maric et al. ${ }^{14}$

Uric acid has an antioxidant effect, however, it becomes astrong oxidant in the environment of metabolic syndrome in which is induced high oxidative stress. ${ }^{15}$ Metabolic syndrome components include hyperglycemia, hypertriglyceridemia, hypertension, obesity and low HDL-cholesterol. ${ }^{9}$ This study shows that serum uric acid has significant correlation with serum fasting plasma glucose and HDLcholesterol. This result is confirmed by Madero et al. ${ }^{16}$ who reported serum uric acid was not affecting kidney damage in normal metabolic person.

An experimental study in America ${ }^{8}$ reported that lowering serum uric acid with allopurinol can inhibit inflammation on kidney which can improve kidney function, proteinuria levels and tubulointerstitial damage, showing that uric acid has a role as a mediator in diabetic nephropathy. ${ }^{5,8}$ Same results were also reported in Korea ${ }^{17}$ and $\operatorname{Iran}^{18}$ that uric acid had a role in kidney damage, because administration of low dosage allopurinol in 
T2DM patients for 4 months can decrease serum uric acid and proteinuria levels.

Limitations of the study were first, this study was incapable to conclude whether hyperuricemia was a cause or a consequence of diabetic nephropathy. Second, this study could not adjust the confounding variables i.e. age, sex, duration T2DM, blood pressure, body mass index, and lipid profile. Therefore, to adjust confounding variables and to know the development of the disease, the result should be confirmed by future prospective cohort and interventional studies.

In conclusions, serum uric acid and proteinuria in T2DM patients were positively correlated. Higher serum uric acid levels were associated with a greater probability of proteinuria which indicated T2DM patients had diabetic nephropathy, suggesting that controlling serum uric acid level in T2DM may prevent diabetic nephropathy.

\section{References}

1. American Diabetes Association. Diagnosis and classification of diabetes mellitus. Diabetes Care. 2012;35(Suppl 1):S64-71.

2. PERKENI. Konsensus Diabetes Melitus Tipe 2 Indonesia 2011. Jakarta: Perkumpulan Endokrinologi Indonesia; 2011.

3. Gardner DG, Shoback D, editors. Greenspan's basic \& clinical endocrinology. 8th ed. New York: The Mc Graw-Hill Companies, Inc.; 2007.

4. Zelmanovitz T, Gerchman F, Balthazar AP, Thomazelli FC, Matos JD, Canani LH. Diabetic nephropathy. Diabetol Metab Syndr. 2009;1(1):10.

5. Jalal DI, Maahs DM, Hovind P, Nakagawa T. Uric acid as a mediator of diabetic nephropathy. Semin Nephrol. 2011;31(5):459-65.

6. Murray RK, Granner DK, Rodwell VW, editors. Harper's illustrated biochemistry. 27th ed. Boston: The McGraw-Hill Companies, Inc.; 2006.

7. Tseng CH. Correlation of uric acid and urinary albumin excretion rate in patients with type 2 diabetes mellitus in Taiwan.
Kidney Int. 2005;68(2):796-801.

8. Kosugi T, Nakayama T, Heinig M, Zhang L, Yuzawa Y, Sanchez-Lozada LG, et al. Effect of lowering uric acid on renal disease in the type 2 diabetic $\mathrm{db} / \mathrm{db}$ mice. Am J Physiol Renal Physiol. 2009;297(2):F481-8.

9. Bonakdaran S, Hami M, Shakeri MT. Hyperuricemia and albuminuria in patients with type 2 diabetes mellitus. Iran J Kidney Dis. 2011;5(1):21-4.

10. Nakagawa T, Mazzali M, Kang DH, Kanellis J, Watanabe S, Sanchez-Lozada LG, et al. Hyperuricemia causes glomerular hypertrophy in the rat. Am J Nephrol. 2003;23(1):2-7.

11. Tervaert TW, Mooyaart AL, Amann $\mathrm{K}$, Cohen AH, Cook HT, Drachenberg $\mathrm{CB}$, et al. Pathologic classification of diabetic nephropathy. J Am Soc Nephrol. 2010;21(4):556-63.

12. National Kidney Disease Education Program. Urine albumin-to-creatinine ratio (UACR) and estimated glomerular filtration rate (eGFR). In: U.S. Department of Health and Human Services NIoH,.2010.

13. Aryal M, Jha B. Assessment of proteinuria as a marker of nephropathy in type 2 diabetes mellitus. Nepal Med Coll J. 2006;8(4):250.

14. Maric C, Sullivan S. Estrogens and the diabetic kidney. Gend Med. 2008;5 Suppl A:S103-13.

15. Chien KL, Chen MF, Hsu HC, Chang WT, Su TC, Lee YT, et al. Plasma uric acid and the risk of type 2 diabetes in a Chinese community. Clin Chem. 2008;54(2):310-6.

16. Madero M, Sarnak MJ, Wang X, Greene T, Beck GJ, Kusek JW, et al. Uric acid and longterm outcomes in CKD. Am J Kidney Dis. 2009;53(5):796-803.

17. Jung DH, Lee YJ, Lee HR, Lee JH, Shim JY. Association of renal manifestations with serum uric acid in Korean adults with normal uric acid levels. J Korean Med Sci. 2010;25(12):1766-70.

18. Momeni A, Shahidi S, Seirafian S, Taheri S, Kheiri S. Effect of allopurinol in decreasing proteinuria in type 2 diabetic patients. Iran J Kidney Dis. 2010;4(2):128-32. 